\title{
Dercum's disease (adiposis dolorosa): a review of clinical presentation and management
}

\author{
Eugeniusz J. Kucharz, Magdalena Kopeć-Mędrek, Justyna Kramza, Monika Chrzanowska, \\ Przemysław Kotyla
}

Department of Internal Medicine, Rheumatology and Clinical Immunology, Medical University of Silesia, Katowice, Poland

\begin{abstract}
Dercum's disease (adiposis dolorosa) is a rare disease of unknown etiology characterized by painful subcutaneous adipose tissue deposits with various localization over the body. The deposits occur histologically as lipomas and are associated with overweight or obesity and a variety of psychiatric disturbances (anxiety, depression, sleep disturbances). Classification of Dercum's disease is related to size and location of adipose nodules (generalized diffuse, generalized nodular, localized nodular and juxta-articular forms). Diagnosis in based on clinical presentation and exclusion of a number of other disorders associated with lipomas. There is no generally accepted management of the patients. Liposuction or lidocaine application has been reported successful in some cases. Other therapeutic methods have been reported but their effectiveness is based on anecdotal descriptions only, and were not confirmed in clinical trials.
\end{abstract}

Key words: Dercum's disease, adiposis dolorosa, subcutaneous fat masses.

\section{Introduction}

Dercum's disease, also known as adiposis dolorosa, is a rare disease typically characterized by development of painful subcutaneous adipose tissue deposits of different size, multiplicity and localization.

The associated symptoms include overweight or obesity, fatigue or weakness and a number of psychiatric manifestations (e.g. sleep disturbances, emotional instability, depression, and anxiety) but the associated symptoms are not a constant component of clinical presentation of the disease.

The etiology of Dercum's disease remains unknown, and disease classification, diagnostic criteria and therapeutic strategy are subject to controversy.

The disease was described for the first time by an American neurologist working in Philadelphia, Francis Xavier Dercum (1856-1931) [1]. He published two papers on the disease in 1888 [2] and 1892 [3], and he used the term "adiposis dolorosa". Further, the disease was reported also in Philadelphia by the American physician James Meschter Anders (1854-1936) [4] and the British physician and medical biographer at Guy's Hospital in London, Sir William Hale White (1857-1949) [5].

Several synonyms of Dercum's disease beside adiposis dolorosa have appeared in medical literature. They include: lipomatosis dolorosa, adiposalgia, adipose tissue rheumatism, fatty tissue rheumatism, lipalgia, neurolipomatosis, and Ander syndrome. Due to unclear etiology and the lack of clear definition, Dercum's disease is also known as Dercum's syndrome.

Dercum's disease has been recognized by the World Health Organization in ICD-10 and is classified as lipomatosis not elsewhere classified (IV - E88.2). Orphanet and the National Organization of Rare Disorders also listed the disease.

The total number of publications on Dercum's disease is estimated at $140-160$ references. A significant majority of them are case reports and only a few papers are analyses of patient cohorts. An excellent review was published in 2012 by Hansson et al. [6], and contained a proposal of classification criteria. The present review is intended to summarize the recent data on the disease 
with emphasis of clinical presentation, differential diagnosis and management.

\section{Epidemiology}

Dercum's disease is a rare disorder appearing almost exclusively in adults, and is predominant in individuals aged 35-50 years [7, 8]. A very few cases of affected children have been published only [9]. It is predominantly a disease affecting women, and the ratio of women to men is estimated at 5-30:1 [4]. The majority of the reported cases concerned Caucasian patients.

Some papers suggested that Dercum's disease occurs predominantly in postmenopausal women. In contrast, studies of Herbst and Asare-Bediako [7] revealed that four-fifths of the female patients developed the disease before menopause. There have been no studies on prevalence or incidence of the disease.

Almost all case descriptions of Dercum's disease are sporadic. A very few reports described familial occurrence of Dercum's disease. The main problem of these case reports is differential diagnosis. Familial tendency was shown in some forms of benign symmetric lipomatosis (Madelung's syndrome), and as implied by name in patients with familial multiple lipomatosis.

Familial clustering of Dercum's disease was reported by Campen et al. [10]. They described two affected siblings whose family included at least 5 affected firstdegree relatives in two generations. Some of the lipomas were painless. The genetic evaluation excluded the 8344A to $\mathrm{G}$ mitochondrial mutation detectable in patients with multiple lipomatoses other than Dercum's disease. They suggested autosomal dominant form of inheritance of the trait. They also suggested that phenotype expression of the disease may vary and Dercum's

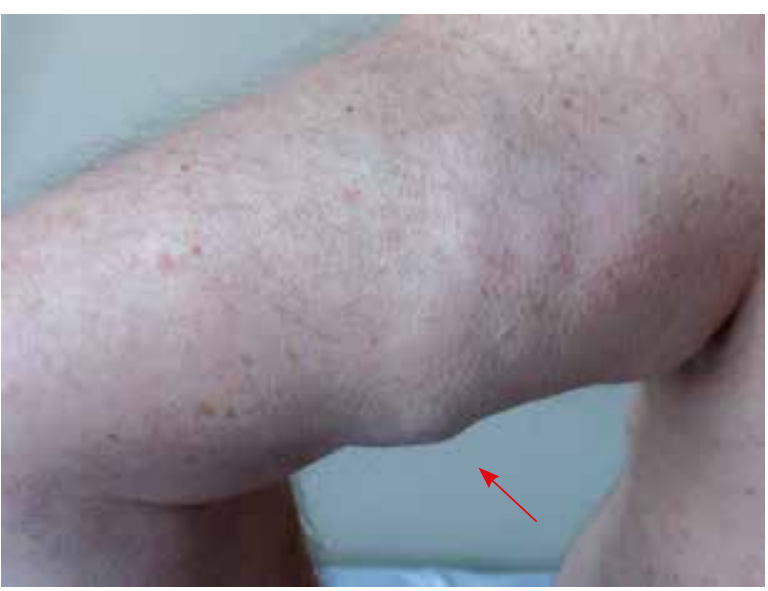

Fig. 1. Changes in the subcutaneous tissue on the patient's shoulder, typical for Dercum's disease. disease may be one of clinical forms of lipomatosis considered in a broad sense.

Autosomal dominant inheritance of the disease was also suggested by Cantu et al. [11], and its familial occurrence was reported by Lynch and Harlan [12]. Despite the above-mentioned reports, all available literature indicates sporadic occurrence of Dercum's disease. It is possible that the disease is heterogeneous and inherited cases are a small subgroup of Dercum's syndrome.

\section{Clinical presentation}

Dercum's disease is characterized by pronounced pain in the adipose tissue. The pain is burning and searing. The pain can be severe, is chronic (> 3 months) and is disabling. It is believed that pain is always associated with smaller or bigger subcutaneous adipose lumps.

In patients with so-called generalized diffuse form of Dercum's disease, the painful deposits can be small and difficult to palpate as opposed to those occurring in nodule form when the lipomas can achieve a large size and mass. The skin over the affected area remains unchanged and lumps are soft, usually well demarcated. There are no signs of altered skin pigmentation or cutaneous breakage. The typical changes of Dercum's disease are presented in Figure 1.

Subcutaneous lipomas may appear in all possible locations. Hansson et al. [6] summarized several descriptions and showed that legs, arms and trunk (anterior or posterior) are the most common body parts with lipomas. The face is affected in about one-fifth of the patients while the scalp and neck are locations of the lipomas in about one-third of individuals suffering from Dercum's disease. Common places of lipomas' development are the buttocks (about 70\%) and thighs. Painful adipose tissue is also common in the subcostal area, the medial aspect of the upper extremity and the lateral and medial parts of the thighs.

The onset of pain is rather slow, but it is also possible that the pain is recognized by the patients with some delay due to its other possible explanations (small injuries, etc.).

Overweight or obesity is considered as the second cardinal symptom after multiple painful adipose masses. Most of the descriptions are concomitant with occurrence of this symptom. Historically, Roux and Vitaut [13] described in 1901 two other cardinal symptoms, i.e. fatigue or weakness and a variety of psychiatric manifestations.

Other investigators suggested that weakness and psychiatric manifestations can be secondary to obesity and chronic pain syndrome. These symptoms are common in patients with Dercum's disease and should be 
taken into account in the clinical diagnosis. They are proposed to be used as diagnostic criteria but there are controversies over which symptoms are cardinal and which are minor.

Psychiatric manifestations associated with Dercum's disease are not found in all the patients. They include depression and emotional instability, sleep disturbances, and less frequently cognitive impairment, dementia and epilepsy. The nature of these symptoms and their relationship with the disease remain unclear.

Depression may be related to chronic pain and occurs in patients with other disorders associated with a long-lasting pain. The same applies to sleep disturbances. Cognitive impairment and even dementia can be associated with metabolic disturbances found in obese individuals. Obesity may also be related to weakness and fatigue. Prominent neurological involvement associated with depression and cognitive impairment was reported in a patient with Dercum's disease [14].

A case control study on depression in Dercum's disease was published by Hansson et al. [15]. They investigated 111 women with the disease and applied the Montgomery Åsberg Depression Rating Scale. The study revealed that $55 \%$ of the patients had light or moderate depression, 44\% were classified as having "no depression", and one patient had severe depression. The conclusion indicated for more common depression is patients with Dercum's disease.

Case descriptions of patients with Dercum's disease indicated a number of other symptoms or signs associated with the disease. It is difficult to distinguish those which are a part of clinical symptomatology of the disease from those that are randomly associated only. Commonly reported symptoms or accompanying disorders include joint and/or muscular pain, constipation, tachycardia, shortness of breath and diabetes. Many of them can also be associated with obesity and all are not specific for Dercum's disease.

Medical literature contains a significant number of atypical presentations of Dercum's disease. Some of them reported different locations of fatty deposits. It should be mentioned that painful lipomas can cause pain of the breast [16]. Despite it being very uncommon, it should be taken into consideration in diagnosis of mastalgia as well as the occurrence of breast lumps. Abdominal pain as a main symptom of the disease [17] and arthralgia as a presenting symptom of Dercum's disease [18] were reported in rare cases. A patient with Dercum's disease complicated by steato-cutaneous necrosis and septic shock was reported by Haddad et al. [19]. Kawale et al. [20] described a patient with fatty lumps of the scalp with severe headache.
Metabolic alterations related to or associated with Dercum's disease are a subject of interesting hypotheses. We reported a case of Dercum's disease in a patient suffering from severe hypercholesterolemia [21]. It is possible that this is unrelated coexistence of two separate disorders, but on the other hand obese patients are prone to various metabolic alterations.

Izar et al. [9] reported an eight-year-old girl suffering from Dercum's disease and hyperbetalipoproteinemia as well as hyperinsulinemia.

Hansson et al. [6] described excess of glucocorticoids, due to medication with hormones as a hypothetical cause of Dercum's disease. Glucocorticoids are known to induce dyslipidemia and it is possible that Dercum's disease has some relationship to altered lipid metabolism.

Łabuzek et al. [22] reported a case of Dercum's disease treated with metformin. The drug is used primarily in obese patients with diabetes mellitus and has a variety of metabolic actions. They found favorable effects of medication on adipokines, $\beta$-endorphin and pro-inflammatory cytokines associated with a decrease in pain. Both metabolic and other mechanisms of action of metformin (e.g. influence on synaptic plasticity, activation of microglia) were hypothetically considered as a mechanism of drug-induced pain reduction in the patient.

Hansson et al. [23] measured different neuropeptides in cerebrospinal fluid and plasma of 53 patients with Dercum's disease. They found a lower level of substance $P$ in cerebrospinal fluid of the patients. Neuropeptide $Y$ level was also borderline lower while some elevation in $\beta$-endorphin level was found in cerebrospinal fluid of the patients. The etiological role of these alterations remains unknown.

Campen et al. [10] proposed an inflammatory pathomechanism, possibly leading to the release of painrelated neuropeptides. The role of trauma has been suggested in some patients [24]. The role of lymphatic vessel dysfunction has also been suggested. According to Rasmussen et al. [25], lymphovascular impairment leads to lymphatic transport deficiency and lipomas appeared to have resulted from defective drainage by lymphatic vessels.

\section{Classification}

A few authors have proposed a classification of subforms of clinical presentation of Dercum's disease. Most of the classifications distinguish three forms of the disease. Recently, Hansson et al. [6] proposed four types of the disease as summarized in Table I.

The classification is based on the following criteria: size of lumps (small in generalized diffuse form, bigger 
Table I. Classification of types of Dercum's disease (based on Hansson et al. [6] with descriptions partially based on Kosseifi et al. [26])

\begin{tabular}{|ll|}
\hline Type & \multicolumn{1}{c|}{ Description } \\
\hline $\begin{array}{l}\text { Type I } \\
\text { Generalized diffuse form }\end{array}$ & $\begin{array}{l}\text { Widespread pain from fatty tissue, very small adipose deposits can be palpated in various } \\
\text { parts of the body but pain can occur in areas without detectable lumps }\end{array}$ \\
\hline $\begin{array}{l}\text { Type II } \\
\text { Generalized nodular form }\end{array}$ & Pain around and in lipomas localized in multiple parts of the body \\
\hline $\begin{array}{l}\text { Type III } \\
\text { Localized nodular form }\end{array}$ & Painful lipomas in limited locations \\
\hline $\begin{array}{l}\text { Type IV } \\
\text { Juxta-articular form }\end{array}$ & Painful folds of fat located inside or very near big joints (the knee, hip or elbow) \\
\hline
\end{tabular}

in all other forms of the disease) and distribution of fatty deposits (widespread versus localized, localized near or within the joints). Thus, the classification is based on descriptive findings and mixed and difficult to categorize forms of Dercum's disease were also reported [26, 27]. Lack of understanding of the etiology and natural history of the disease results in a lack of possibility to create a pathophysiological classification.

\section{Laboratory and pathological findings}

There are no specific laboratory tests facilitating diagnosis of Dercum's disease. Histopathological evaluation of fat mass reveals lipomas without signs of inflammation. Herbst at al. [28] described a higher level of connective tissue in fat biopsy samples in patients with Dercum's disease. In general, most of the reports indicated that the pathological picture of the fat masses

Table II. Differential diagnosis of Dercum's disease

\begin{tabular}{|l|}
\hline Generalized diffuse and generalized nodular forms \\
\hline Fibromyalgia \\
\hline Lipoedema \\
\hline Lymphedema \\
\hline Proteus syndrome \\
\hline Weber-Christian disease \\
\hline Fröhlich's syndrome \\
\hline Progressive lipodystrophy \\
\hline Cushing's syndrome \\
\hline Hypothyroidism \\
\hline Nodular forms \\
\hline Benign symmetric lipomatosis (Madelung's syndrome, \\
Launois-Bensaude syndrome) \\
\hline Familial multiple lipomatosis \\
\hline Neurofibromatosis type 1 \\
\hline Adenolipomatosis \\
\hline Multiple endocrine neoplasia I (MEN I) \\
\hline
\end{tabular}

in patients with Dercum's disease is indistinguishable from lipomas [29].

\section{Imaging appearance}

Ultrasound and magnetic resonance imaging revealed that the lesions were located in the superficial subcutaneous fat. There were no changes in the deep fat. In most of the cases, imaging techniques detected more lesions than physical evaluation of the patients. It indicates that most of the lesions are clinically asymptomatic.

In study of Tins et al. [30] most lesions were $<2 \mathrm{~cm}$ in diameter and were oblong with the long axis parallel to the skin. All lesions were hyperechoic on ultrasound and showed no demonstrable flow on Doppler imaging. There was no edema in or around the lesions. Magnetic resonance imaging revealed a blush-like appearance with a decreased T1-weighted signal and an increased signal in the water-sensitive sequence (STIR). Larger lesions were more inhomogeneous in appearance. There was no difference between symptomatic and asymptomatic lesions [30].

\section{Diagnosis and differentiation}

Physical examination and medical history revealing painful lipomas consisting of normal adipose tissue and pain localized in the adipose tissue in a person with at least overweight should be followed by careful exclusion of other painful conditions. The accompanying symptoms and signs should be taken into consideration.

A number of disorders can be akin to Dercum's disease and should be excluded. Differential diagnoses are listed in Table II.

The most common and sometimes difficult to differentiate with the generalized form of Dercum's disease are fibromyalgia, lipoedema, panniculitis, lymphedema, and others.

Fibromyalgia is in some cases difficult to distinguish from Dercum's disease. It is a widespread muscular pain 
with several psychiatric manifestations. Detection of painful lipomas may be helpful in the distinction of these two disorders. Lipoedema is usually limited to lower extremities, and is characterized by bilateral symmetric occurrence and homogeneous deposition of fat [31].

Panniculitis is associated with inflammation and in some cases with vasculitis. The nodules are erythematous and some of them heal and others develop. The lower extremities are common locations of panniculitis. Lymphedema results from accumulation of protein-rich interstitial fluid within the skin and responds to compression or lymphatic massage [32]. Differential diagnosis of Dercum's disease massive localized lymphedema may be difficult [33].

\section{Treatment}

The treatment strategy in patients with Dercum's disease is based on the individual decision of the physician, because only a few studies have been published and most of the reports described a single case.

Liposuction is a method of management of Dercum's disease that is relatively commonly reported in the literature. Most of the described case were operated on with "dry" technique and only a few with tumescence technique [6, 34].

Hansson et al. [35] reported a decrease in pain in 53 patients operated on with liposuction. Diminished pain was revealed with both subjective and objective measurements. In a long-term observation, it was found that the pain relief diminished over time, but after 5 years still pain indices were lower than in inoperable subjects with Dercum's disease and were lower than baseline values before liposuction. The same group of researchers also found a slight improvement in quality of life after liposuction [36].

The mechanism of pain reduction after liposuction remains unclear. Destruction of nerve plexuses within the adipose tissue was suggested. Reduction of altered fat masses seems to be the main cause of pain reduction because pain diminution lasted longer than sensitivity loss after liposuction [36]. There was no significant difference in thermal and vibratory thresholds 3 and 12 months after liposuction in patients with Dercum's disease [37]. Liposuction was also applied in cases of juxta-articular form of the disease [38].

Surgical treatment was administered in a few reported cases. Lipectomy or dermolipectomy was described as a method of amelioration of the disease, also in juxta-articular form $[39,40]$.

Subcutaneous adipose tissue therapy based on deep fat tissue, fascia and muscle massage has been recently suggested as a method facilitating reduction of lipomas in Dercum's disease [41].

Pharmacological management mostly focuses on analgesics. Patients with Dercum's disease are considered as refractory to non-steroidal anti-inflammatory drugs [6], but some reports indicated an opportunity to obtain pain reduction with non-steroidal anti-inflammatory drugs [7]. Lidocaine is used commonly either in the form of intralesional injections, transdermal application or intravenous infusions [26, 42, 43]. The mechanism of its action is not fully understood but blocking of impulses conduction in peripheral nerves and the effect of sympathetic activity are suggested mechanisms of therapeutic action of lignocaine.

Transcutaneous frequency rhythmic electrical stimulation was reported as an effective and safe method of treatment [44].

Single reports on beneficial effects of pregabalin, interferon $\alpha-2 b$, corticosteroids, metformin and calcium-channel modular as well as infliximab with methotrexate were published [6, 22, 45-47]. Herbs and Rutledge [48] performed a study on 10 patients with Dercum's disease and revealed that dynamic whole body cyclic pneumatic compression resulted in pain relief.

Recently, deoxycholic acid was used for management of Dercum's disease. Deoxycholic acid was approved for the reduction of submental fat. Recently, Wipf et al. [49] reported novel, highly effective use of deoxycholic acid in the form of injections to manage lipomas in a patients with Dercum's disease. This method of management of the patients needs further evaluation.

Summing up: There is no recommended strategy of management of patients with Dercum's disease. In general, it is a chronic condition with a strong tendency to recurrence. The decision on the therapeutic strategy should be based on an analysis of type of the disease and severity of symptoms. In more localized forms reduction of fat masses resulted in relief and flares were usually observed after a few years. In generalized forms, the physician is advised to consider pharmacological methods, but there is no evidence of their efficacy. Additional management, including antidepressants, psychotherapy and patient education, is suggested.

\section{Conclusions}

Dercum's disease is still a very enigmatic clinical item, and various aspects of its etiopathogenesis, clinical presentation and management are unresolved.

The disease is diagnosed on the basis of clinical findings and the question of its heterogeneity should be addressed. It remains unclear whether Dercum's disease is a syndrome or homogeneous nosological unit. It 
can be hypothesized that a few unrelated factors may result in pain development within accumulations of fatty tissue. In such cases, Dercum's disease is a syndrome secondary to a group of etiological factors, and only cases with an evidenced genetic background will be defined as a nosological unit. Despite this question, currently diagnosis can be made only on the basis of pain related to deposits of the adipose tissue.

Management is empirical, focused on pain and in a limited situation on elimination (with surgical procedures or liposuction) of an excess of fatty tissue. The mechanism of pain development within the adipose tissue is unknown; thus various therapeutic methods have been reported to be effective. Most of the reports consisted of anecdotic descriptions and there is a lack of prospective studies.

Despite the lack of understanding of the disease, it should be better recognized by rheumatologists, general practitioners and dermatologists, and more investigations including multicenter studies should be carried out.

\section{The authors declare no conflict of interest.}

\section{References}

1. Patel DA, Swan KG. Francis Xavier Dercum: a man for all seasons. Ann Clin Transl Neurol 2014; 1: 233-237.

2. Dercum FX. A subcutaneous connective tissue dystrophy of the arms and back, associated with symptoms resembling myxedema. Univ Med Mag (Philadelphia) 1888; 1: 1-11.

3. Dercum FX. There cases of a hitherto unclassified affection resembling in its grosser aspects obesity, but associated with special nervous symptoms - adiposis dolorosa. Am J Med Sci 1892; 101: 521-523.

4. Anders JM. A Textbook Of The Practice Of Medicine. W.B. Saunders \& Company, Philadelphia 1897.

5. White WH. A case of adiposis dolorosa. Br Med J 1899; 2: 1533-1534.

6. Hansson E, Svensson H, Brorson H. Review of Dercum's disease and proposal of diagnostic criteria, diagnostic methods, classification and management. Orphanet J Rave Dis 2012; 7: 23.

7. Herbst KL, Asare-Bediako S. Adiposis Dolorosa in More than Painful Fat. Endocrinologist 2007; 17: 326-334.

8. Wortham NC, Tomlinson IP. Dercum's disease. Skinmed 2005; 4: 157-162.

9. Izar MCO, da Fonseca HAR, França CN, et al. Rare presentation of Dercum's Disease in a child with Abnormalities in Lipoprotein Metabolism. Arq Bras Cardiol 2018; 111: 755-757.

10. Campen R, Mankin H, Louis DN, et al. Familial occurrence of adiposis dolorosa. J Am Acad Dermatol 2001; 44: 132-136.

11. Cantu JM, Ruiz-Barquin E, Jimenez M, et al. Autosomal dominant inheritance in adiposis dolorosa (Dercum's disease). Humangenetik 1973; 18: 89-91.

12. Lynch HT, Harlan WL. Hereditary factors in Adiposis Dolorosa (Dercum's Disease). Am J Hum Genet 1963; 15: 184-190.
13. Roux J, Vitaut M. Maladie de Dercum (Adiposis dolorosa). Revue Neurol (Paris) 1901; 9: 881-888.

14. Cantone M, Lanza G, Pennisi M, et al. Prominent neurological involvement in Dercum disease. J Neurol 2017; 264: 796-798.

15. Hansson E, Svansson H, Brorson H. Depression in Dercum's disease and in obesity: a case control study. BMC Psychiatry 2012; 12: 74.

16. Trentin C, Di Nubila B, Cassano E, Bellomi M. A rare cause of mastalgia: Dercum's disease (adiposis dolorosa). Tumori 2008; 94: 762-764.

17. Atkinson RL. Adiposis dolorosa as an etiology of abdominal pain. Wien Klin Wochenschr 2008; 120: 251.

18. Amine B, Leguilchard F, Benhamou CL Dercum's disease (adiposis dolorosa): a new case-report. Joint Bone Spine 2004; 71: 147-149.

19. Haddad D, Athmani B, Costa A, Cartier S. Maladie de Dercum: une complication grave au cours d'une maladie rare. À propos d'un cas. Ann Chir Plast Estét 2005; 50: 247-250.

20. Kawale J, Mahore A, Dange N, Bhoyar K. Adiposis dolorosa of scalp presenting with severe headache: an unusual case. J Headache Pain 2010; 11: 539-541.

21. Szypuła I, Kotulska A, Szopa M, et al. Adiposis dolorosa with hypercholesterolemia and premature severe generalized atherosclerosis. Wiad Lek 2009; 62: 64-65.

22. Łabuzek K, Liber S, Suchy D, Okupień B. A successful case of pain management using methformin in a patient with adiposis dolorosa. Int J Clin Pharmacol Ther 2013; 51: 517-524.

23. Hansson E, Manjer J, Svensson H, et al. Neuropeptide levels in Dercum's disease (adiposis dolorosa). Reumatismo 2012; 64: 134-141.

24. Hao D, Olugbodi A, Udechukwu N, Donato AA. Trauma-induced adiposis dolorosa (Dercum's disease). BMJ Case Rep 2018; 2018: pii; bcr-2017-223869.

25. Rasmussen JC, Herbst KL, Aldrich MB, et al. An abnormal lymphatic phenotype is associated with subcutaneous adipose tissue deposits in Dercum's disease. Obesity 2014; 22: 2186-2192.

26. Kosseifi S, Anaya E, Dronovalli G, Leicht S. Dercum's disease an unusual presentation. Pain Med 2010; 11: 1430-1434.

27. Kucharz EJ, Kramza J, Kotyla P, Kotulska A. Mixed generalized/ juxta-articular form of Dercum's disease. Reumatologia 2016; 54: 212

28. Herbst KL, Coviello AD, Chang A, et al. Lipomatosis-associated inflammation and excess collagen may contribute to lower relative resting energy expenditure in women with adiposis dolorosa. Int J Obes (Lond) 2009; 33: 1031-1038.

29. Hansson E, Svensson H, Stenram U, Brorson H. Histology of adipose tissue inflammation in Dercum's disease, obestity and normal weight controls: a case control study. J Inflamm (Lond) 2011; 8: 24.

30. Tins BJ, Matthews C, Haddaway M, et al. Adiposis dolorosa (Dercum's disease): MRI and ultrasound appearances. Clin Radiol 2013; 68: 1047-1053.

31. Chen SG, Hsu SD, Chen TM, Wang HJ. Painful fat syndrome in a male patient. Br J Plast Surg 204; 57: 282-286.

32. Buck DW II, Herbst KL. Lipedema: A Relatively Common disease with Extremely Common Misconceptions. Plast Reconstr Surg Glob Open 2016; 4: e1043. 
33. Petscavage-Thomas JM, Walker EA, Bernard SA, Bennett J. Imaging finding of adiposis dolorosa vs. massive localized lymphedema. Skeletal Radiol 2015; 44: 839-847.

34. Wollina U, Goldman A, Heinig B. Microcannular tumescent liposuction in advanced lipedema and Dercum's disease. G Ital Dermatol Venerol 2010; 145: 151-159.

35. Hansson E, Svensson $\mathrm{H}$, Brorson $\mathrm{H}$. Liposuction may reduce pain in Dercum's disease (adiposis dolorosa). Pain Med 2011 12: 942-952.

36. Hansson E, Manjer J, Svensson H, Brorson H. Quality-of-life in patients with Dercum's disease - before and after liposuction. J Plast Surg Hand Surg 2012; 46: 252-256.

37. Hansson E, Svensson H, Rosén I, Brorson H. Thermal and vibratory thresholds after liposuction in patients with Dercum's disease. J Plast Surg Hand Surg 2011; 45: 72-76.

38. De Silva M, Earley MJ. Liposuction in the treatment of juxtaarticular adiposis dolorosa. Ann Rheum Dis 1990; 49: 403-404

39. Wollina U, Heining B, Langer D, Nowak A. Juxta-articular adiposis dolorosa (Dercum's disease type IV): report of four cases and treatment by dermolipectomy. Wien Med Wochenschr 2015; 165: 374-377.

40. Held JL, Andrew JA, Kohn SR. Surgical Amelioration of Der cum's Disease: a Report and Review. J Dermatol Surg Onco 1989; 15: 1294-1296.

41. Ibarra $M$, Eekema A, Ussery $C$, et al. Subcutaneous adipose tissue therapy reduces fat by dual X-ray absorptiometry scan and improves tissue structure by ultrasound in women with lipoedema and Dercum disease. Clin Obes 2018; 8: 398-406.
42. Desai MJ, Siriki R, Wang D. Treatment of pain in Dercum's disease with Lidoderm (Lidocaine $5 \%$ patch): a case report. Pain Med 2008; 9: 1224-1226.

43. Petersen P, Kastrup J. Dercum's disease (adiposis dolorosa). Treatment of the severe pain with intravenous lidocaine. Pain 1987; 28: 77-80.

44. Martinenghi S, Caretto A, Losio C, et al. Successful treatment of Dercum's disease by Transcutaneous Electrical Stimulation: a Case Report. Medicine (Baltimore) 2015; 94: e950.

45. Lange U, Oelzer P, Uhlemann C. Dercum's disease (Lipomatosis dolorosa): successful therapy with pregabalin and manual lymphatic drainage and a current overview. Rheumatol Int 2008; 29: 17-22.

46. Gonciarz Z, Mazur W, Hartleb J, et al. Interferon alfa-2b induced long-term relief of pain in two patients with adiposis dolorosa and chronic hepatitis C. J Hepatol 1997; 27: 1141.

47. Singal A, Janiga JJ, Bossenbroek NM, Lim HW. Dercum's disease (adiposis dolorosa): a report of improvement with infliximab and methotrexate. J Eur Acad Dermatol Venereol 2007; 21: 717.

48. Herbst KL, Rutledge T. Pilot study: rapidly cycling hypobaric pressure improves pain after 5 days in adiposis dolorosa. J Pain Res. 2010; 3: 147-153.

49. Wipf A, Lofgreen S, Miller DD, Farah RS. Novel Use of Deoxycholic Acid for Adiposis Dolorosa (Dercum disease). Dermatol Surg 2019; 10.1097/DSS.0000000000001800 [Epub ahead of print]. 